Dealing with the source of cometary gases, reference is made to Whipple's cometry model (Astrophys. J., 111,$375 ; 1950$, and 113,$464 ; 1951$ ), which envisages the nucleus as a conglomeration of frozen solids, such as water, ammonia, methane, carbon dioxide or carbon monoxide, and possibly other materials, combined with meteoric matter, all initially at a temperature below $50^{\circ} \mathrm{K}$. As the comet approaches the Sun, the frozen solids vaporize and so provide the parent molecules which, upon photo-dissociation, give the radicals the spectra of which we observe. Donn and Urey have suggested a modification of Whipple's model (Astrophys. J., 123, 339 ; 1956) to include both stable and reactive molecules, yielding radicals which could lead to actual chemical explosions to explain observed cometary activity. They give examples of a number of laboratory experiments involving $\mathrm{NH}$ and azides, $\mathrm{OH}$ and hydrogen peroxide, etc., that could conceivably occur if concentration of the necessary radicals and other molecules were present in the matrix. It appears, therefore, that solar radiation or corpuscles need only act as a trigger for the strongly exothermic reactions which provide their own excess of energy in the explosion.

\section{Proceedings of the Royal Institution}

THE Proceedings of the Royal Institution are to be published three times a year in future instead of annually; one advantage of the new procedure will be that the discourses will appear in print soon after their delivery. Thus, Vol. 37, Part 1, No. 165, which is the first to appear under the new arrangement, opens with the discourse on gemstones given by Sir Lawrence Bragg on January 31, 1958, and includes five other discourses given before Easter. It is also intended to publish once a year a famous discourse given at the Royal Institution a hundred years ago. The Proceedings are available to non-members at 8s. $6 d$. per issue, or $21 s$. a year, from January 1,1959 (from the Royal Institution, 21 Albemarle Street, London, W.1).

\section{"Rejection of the Peroxide Accumulation Hypo-} thesis of Isoniazid Action"

Dr. Frank Winder, Laboratories of the Medical Research Council of Ireland, Trinity College, Dublin, writes: "In a communication under this title in Nature of April 26, p. 1203, Holmes and Rubbo state that 'Sodium nitrite . . . reduces free peroxide, and reacts rapidly with the catalase-peroxide complex . . . The first portion of this statement is true only when the $p \mathrm{H}$ is well on the acid side. To check this, $50 \mu \mathrm{gm}$. per $\mathrm{ml}$. hydrogen peroxide were incubated with $500 \mu \mathrm{gm}$. per ml. sodium nitrite for $24 \mathrm{hr}$. in phosphate buffers over the $p \mathrm{H}$ range 5-7. The peroxide was then estimated by methods which did not involve acidification, for example, by using peroxidase or luminol. The nitrite caused no significant destruction of the peroxide in any of these buffers".

\section{The Night Sky in September}

New moon occurs on Sept. 13d. 12h. 02m. U.T., and full moon on Sept. $27 \mathrm{~d}$. $21 \mathrm{~h} .43 \mathrm{~m}$. The following conjunctions with the Moon take place : Sept. 4d. $21 \mathrm{~h}$., Mars $0 \cdot 5^{\circ}$ N. ; Sept. 16d. 07h., Jupiter $0 \cdot 2^{\circ}$ N. ; Sept. 19d. 15h., Saturn $3^{\circ}$ S. In addition to these conjunctions with the Moon, Mercury is in conjunc. tion with Venus on Sept. 5d. 02h., Mercury being $2 \cdot 1^{\circ}$ S., Venus with Regulus on Sept. 8 d. 17h., Venus being $0.7^{\circ}$ N., Mercury with Regulus on Sept. 10d. $09 \mathrm{~h}$., Mercury being $0.0^{\circ}$ N., and Mercury with Venus on Sept. 18d. 06h., Mercury being $0.3^{\circ} \mathrm{N}$. Mercury is favourably placed for observation during the first fortnight of the month, and is a morning star, rising at about 4h.; during this period its stellar magnitude increases from $+1 \cdot 6$ to $-0 \cdot 7$. Venus is also a morning star, visible low in the southeast before sunrise. It rises at $3 \mathrm{~h} .30 \mathrm{~m} ., 4 \mathrm{~h} .10 \mathrm{~m}$. and $5 \mathrm{~h} .0 \mathrm{~m}$. on September 1,15 and 30 , respectively ; its stellar magnitude is $-3 \cdot 3$. During the month its distance from the Earth increases from 149 to 156 million miles and the visible portion of the apparent disk from 0.947 to 0.982 . Conditions for observation are rather unfavourable at the end of the month. Mars rises at $21 \mathrm{~h} .20 \mathrm{~m}$., $20 \mathrm{~h} .35 \mathrm{~m}$. and $19 \mathrm{~h} .45 \mathrm{~m}$. at the beginning, middle and end of the month, respec. tively. Its stellar magnitude increases during the month from -0.5 to $-1 \cdot 1$, its distance from the Earth decreasing from 70 to 56 million miles. Mars enters Taurus on September 1, and continues moving eastwards among the stars; it is south of the Pleiades on September 13-16. Jupiter is too close to the Sun for satisfactory observation. Saturn sets at $22 \mathrm{~h} .30 \mathrm{~m} ., 21 \mathrm{~h} .35 \mathrm{~m}$. and $20 \mathrm{~h} .40 \mathrm{~m}$. at the beginning, middle and end of the month, respectively ; it is near $\theta$ Ophiuchi. It has a stellar magnitude of +0.7 and a distance of 935 million miles from the Earth on September 15. Occultations of stars brighter than magnitude 6 are as follows, observations being made at Greenwich: Sept. 7d. 01h. 46.6m., 115 Tau. $(R)$; Sept. 9d. 02h. 12.8m., 入 Gem. $(D)$; Sept. 9d. 03h. 02.0m., $\lambda$ Gem. $(R)$; Sept. 21d. 19h. $08 \cdot 9$ m., p Sgr. $(D)$; Sept. 22 d. $23 \mathrm{~h}$. $18 \cdot 2 \mathrm{~m}$., $\beta$ Cap. $(D)$. $R$ and $D$ refer to reappearance and disappearance, respectively. The autumnal equinox occurs on Sept. 23d. 13h.

\section{Announcements}

THE nineteenth national conference of the Council for the Preservation of Rural England, on "Rural Problems of the Moment", will be held in Cheltenham during October 16-18. Further information can be obtained from the Secretary of the Council, 4 Hobart Place, London, S.W.1.

Tre first electronic computer exhibition in Europe will be held at Olympia, London, during November 28-December 4. A business computer symposium will be held concurrently. Further information can be obtained from Mrs. S. S. Elliott, 11/13 Dowgate Hill, London, E.C.4.

The Institute of Physies, one of the constituent bodies of the British Nuclear Energy Conference, is arranging a Symposium in London on "Nuclear Fuel Cycles", on January 22 and 23, 1959. The papers which have been invited cater mainly for those working in the field, and will deal with the applied physics aspects of the fuel cycles which form the basis of the immediate nuclear power programme. Application to attend the Symposium should be made to the Secretary, Institute of Physics, 47 Belgrave Square, London, S.W.1. Proceedings of the Symposium will be published in the Jorrnal of the British Nuclear Energy Conference. 